performed in 7 infants and MRI in 1 revealed bilateral lesions, chiefly frontal and parietal. The extent of cerebral damage was not correlated with neurodevelopmental outcome. Eight children had cerebral palsy; 5 were mentally retarded, severe in $3 ; 7$ exhibited deficits in attention; 8 had expressive language problems; and 3 attended special education classes. Relapse with reactivation of vesicles and leading to behavioral deterioration occurred in 1 child. (Engman M-L, Adolfsson I, Lewensohn-Fuchs I, et al. Pediatr Neurol June 2008;38:398-405). (Respond: Dr Engman, Division of Pediatrics, Children's Hospital B57, Karolinska University Hospital, Stockholm, Sweden. E-mail: mona-lisa.engman(aki.ke).

COMMENT. Seizures with abnormalities in the EEG should alert to a possible diagnosis of neonatal herpes virus encephalitis. Neuropsychological investigation is recommended early as a measure of outcome and the detection of relapse.

\title{
VIRAL ENCEPHALITIS AND EPILEPSY
}

The role of viral meningitis in the cause of epilepsy is reviewed by researchers from Sanjay Gandhi Postgraduate Institute of Medical Sciences, Lucknow, India; and University of Malaya, Kuala Lumpur, Malaysia. Viral meningitis presents with seizures in the acute stage, and increases the risk of late unprovoked seizures and epilepsy. Among sporadic viral encephalitides, herpes simplex virus is most frequently associated with epilepsy, probably because it involves the highly epileptogenic frontotemporal cortex. Among the epidemic viral encephalitides, usually due to flaviviruses, Japanese encephalitis is most common; it is associated with acute symptomatic seizures in $7-46 \%$ of children affected. Equine, St Louis, and West Nile viruses, and measles, varicella, mumps, influenza, and entero-viruses may also present with acute symptomatic seizures. The risk of late unprovoked seizures and epilepsy following viral encephalitides is not well determined, and requires prospective studies. The authors propose that the anatomical localization of lesions during the acute viral infection may determine the occurrence and outcome of postencephalitic epilepsy. (Misra UK, Tan CT, Kalita J. Viral encephalitis and epilepsy. Epilepsia Aug 2008;49(Suppl 6):13-18). (Respond: Dr Usha Kant Misra, Department of Neurology, Sanjay Gandhi Postgraduate Institute of Medical Sciences, Lucknow-226014. E-mail: ukmisra(usgpgi.ac.in).

COMMENT. This Epilepsia supplement is the consensus following a meeting in Feb 2007, arranged at Chandigarh, India by the International League Against Epilepsy, concerning CNS infections as a cause of epilepsy (Singh G et al. Epilepsia Aug 2008;49(Suppl 6):1). In addition to viral encephalitis, the association between epilepsy and meningitis, cerebral malaria, T solium cysticercosis, and HIV infection were discussed and reviewed. The meeting focused on unremitting long-term seizure activity following CNS infections, and provided suggestions for future research in this neglected area. 